\section{Transformações socioculturais da alimentação hospitalar}

\section{Sociocultural}

transformations in hospital food

Andresa Michele Godoy

Faculdade de Ciências Sociais Pontifícia Universidade Católica de Campinas Rua Abe Assis, 155

12900-000 Bragança Paulista - SP - Brasil andresagodoy@yahoo.coml

Doraci Alves Lopes

Faculdade de Ciências Sociais Pontifícia Universidade Católica de Campinas Av. Copacabana, 95/1165 Condomínio San Conrado

13104-082 Campinas - SP - Brasil doraci@puc-campinas.edu.br]

\section{Rosa Wanda Diez Garcia}

Curso de Nutrição e Metabolismo Faculdade de Medicina de Ribeirão Preto

Universidade de São Paulo

Av. dos Bandeirandes, 3900

14049-900 Ribeirão Preto - SP - Brasil wanda@fmrp.usp.br
GODOY, Andresa Michele; LOPES, Doraci Alves; GARCIA, Rosa Wanda Diez.

Transformações socioculturais da alimentação hospitalar. História, Ciências, Saúde Manguinhos, Rio de Janeiro, v.14, n.4, p.1197-1215, out.-dez. 2007.

$\mathrm{O}$ artigo busca no passado os elementos constituintes da cultura alimentar hospitalar, com o objetivo de encontrar as raízes históricas da alimentação em instituições hospitalares. Pressupõe-se que a dieta não seja apenas resultante de procedimentos tecnocientíficos, mas também historicamente construída, criada e recriada perante aspectos econômicos e socioculturais. Realizou-se um mapeamento inicial em arquivos universitários, municipais e hospitalares de Campinas (SP), além de entrevistas com trabalhadores dos serviços de alimentação de três instituições hospitalares. Conclui-se que a valorização de ações e intervenções associadas à tecnologia, em detrimento daquelas identificadas com o universo doméstico, pode ter contribuído para certa negligência dos hospitais com a alimentação, considerada uma área de pouca importância.

PALAVRAS-CHAVE: dieta hospitalar; história de instituições de saúde; cultura institucional; alimentação institucional.

GODOY, Andresa Michele; LOPES, Doraci Alves; GARCIA, Rosa Wanda Diez.

Sociocultural transformations in hospital food. História, Ciências, Saúde - Manguinhos, Rio de Janeiro, v.14, n.4, p.1197-1215, Oct.-Dec. 2007.

The article seeks to identify the historical roots of food culture in hospital settings. It assumes that diet is not merely the result of technical and scientific concerns but is also historically constructed, created, and recreated in response to economic and sociocultural elements. The study conducted a preliminary survey of university, municipal, and hospital archives in Campinas, São Paulo, and included interviews with food service workers at three hospital institutions. Our conclusion is that more value has been placed on initiatives and actions related to technology than on initiatives identified with the domestic world; this may have contributed to a certain tendency for hospitals to neglect the issue of food, deemed of minor importance.

KEYWORDS: hospital diet; history of medical institutions; institutional culture; institutional food. 
A busca dos elementos constituintes da cultura alimentar hos pitalar orientou este trabalho, cujo objetivo foi buscar as raízes históricas da alimentação em instituições hospitalares, pressupondo que a dieta hospitalar seja não apenas baseada em procedimentos tecnocientíficos, mas também historicamente construída, criada e recriada em função de aspectos econômicos e socioculturais. O interesse por esta abordagem histórico-sociológica da alimentação hospitalar emergiu durante o desenvolvimento de um estudo sobre as representações sociais das dietas hospitalares (Garcia, 2006).

O aspecto nutricional do paciente hospitalizado foi enfatizado na década de 1970, quando se constatou a alta incidência de desnutrição intra-hospitalar e seu impacto na morbidade e mortalidade (Bollet, Owens, 1973; Blackburn et al., 1977; Bristian et al., 1974). Os métodos para diagnóstico e tratamento da desnutrição hospitalar foram então aperfeiçoados, sem desencadear, todavia, uma correspondente preocupação com a alimentação hospitalar.

Já em 1860, Nightingale (1989) enumerava indicadores do descuido com a alimentação do paciente hospitalizado - problemas no horário da alimentação hospitalar e fome na internação devida à inobservância das necessidades do doente. Kandela (1999) aponta a falta de interesse da comunidade médica por esse tema, referindose à permanência de problemas relacionados à alimentação hospitalar documentados na década de 1940.

As características de instituições sociais e hospitais com uma longa trajetória refletem teorias sobre a doença, necessidades impostas pela sociedade e forças históricas. Os hospitais foram instituições religiosas, cujos dogmas orientaram seus propósitos. Estruturaram-se não como local de cura ou de prorrogação da vida, mas sim para a prática da caridade, e acolhiam não só os enfermos, mas todos aqueles que necessitavam asilo (Coe, 1973).

O hospital iniciou sua função terapêutica no final do século XVIII, quando passou a ser aberto à visitação e observação sistemática. Antes era essencialmente uma instituição de assistência aos pobres e de segregação e exclusão do doente, servindo assim tanto para recolher os doentes quanto para proteger os demais do perigo que representavam. A assistência material e espiritual concentrava-se nos últimos cuidados e no sacramento. O pessoal do hospital praticava a caridade para conseguir a própria salvação (Foucault, 1996). Atualmente o hospital é uma estrutura complexa, definida por prover leitos, alimentação e cuidados de enfermagem constantes, circunscritos numa terapia médica, com o objetivo de recuperar a saúde do paciente (McKee, Healy, 2002)

Para compreender uma instituição convém entender o processo histórico que a envolve, bem como as formas de controle que estabelecem seus padrões de conduta. A rotina, os papéis desempe- 
nhados pelos indivíduos e a história sedimentam as experiências interiorizadas pelo sujeito as quais legitimam uma cultura institucional. Ações freqüentemente repetidas são moldadas em um padrão que pode ser reproduzido sem esforço, estreitando as opções e institucionalizando as ações (Berger, Luckmann, 1987).

A atitude das instituições hospitalares perante a alimentação foi investigada em pesquisa documental, complementada com entrevistas concedidas por funcionários de instituições hospitalares do município de Campinas (SP). Na primeira fase exploratória do estudo (Chizzoti, 1988), foram consultados os acervos da Biblioteca Municipal de Campinas, do Centro de Memória da Unicamp e do Arquivo Edgard Leuenroth - Centro de Pesquisa e Documentação Social da Universidade de Campinas (Unicamp), e ainda o Centro de Cultura, Letras e Artes de Campinas (CCLAC). Averiguou-se a existência de documentação dos hospitais e foram realizadas duas entrevistas. A primeira, com Domenico Feliciello, autor de estudo sobre o ensino médico no Brasil Império (Feliciello, 2002), médico e pesquisador na área de história do ensino médico, contribuiu para elucidar o passado de instituições hospitalares e situar o ensino nelas praticado no contexto do sistema de saúde no Brasil. A segunda entrevista, concedida pela nutricionista de um dos hospitais da cidade, forneceu informações importantes sobre aspectos históricos da cozinha do hospital, uma vez que a entrevistada mantém consigo documentos antigos do serviço de nutrição, sobretudo dietas.

Nos hospitais investigados não é comum a preservação de registros antigos relacionados à alimentação hospitalar. Nas bibliotecas desses hospitais encontram-se predominantemente documentos oficiais como relatórios, cadernos de registros e boletins, ou aqueles publicados em datas comemorativas da instituição.

Os primeiros hospitais de Campinas foram criados nas últimas décadas do século XIX, em geral devido a surtos epidêmicos. Outros surgiram na década de 1950, de intenso desenvolvimento econômico e industrial no país - fase conhecida como nacionaldesenvolvimentista -, associado a avanços tecnológicos em todas as áreas de conhecimento, inclusive a saúde. A Real Sociedade Portuguesa de Beneficência, a Maternidade de Campinas e o Hospital Álvaro Ribeiro, fundados respectivamente em 1879, 1913 e 1936, foram selecionados para estudo por estarem entre os mais antigos e por dispor de alguma documentação a eles referente.

A escassez de documentos e a necessidade de preencher lacunas com métodos complementares de pesquisa (Lang, 1992) nos levaram a recorrer à história oral. O propósito foi registrar, por meio de entrevistas, representações que profissionais e trabalhadores do setor de alimentação hospitalar elaboram sobre a atividade. Os entrevistados foram selecionados entre aqueles que participaram pelo 
menos durante 15 anos do planejamento ou da produção de alimentação hospitalar nos hospitais selecionados para estudo (Neves, 2000; Quadro 1). Assim, além das fontes escritas, o estudo lançou mão de reconstituições das experiências de sujeitos sociais no que se refere às suas relações com os hospitais, levando-se em conta os papéis desempenhados.

\section{Quadro I - Entrevistados}

\begin{tabular}{|c|}
\hline $\begin{array}{c}\text { Cozinheira: nascida em 1948, começou a trabalhar como copeira no hospital } \\
\text { em 1976; por ocasião da entrevista trabalhava como cozinheira. }\end{array}$ \\
\hline Administrador: nascido em 1930, começou a trabalhar em 1964 e é \\
administrador de uma das instituições.
\end{tabular}

As instituições estudadas estão estreitamente ligadas à história de Campinas. Foram fundadas em virtude do crescimento da região e da necessidade de resolver os problemas da área da saúde. A imigração foi fundamental para o aumento da cidade e para a constituição do espaço urbano-metropolitano da região, desde o final do século XIX (Baeninger, 1996). Diversas instituições foram fundadas por colônias de imigrantes, entre elas a Sociedade Portuguesa de Beneficência (1873), cujo hospital foi inaugurado em 20 de julho de 1879, segundo o seu Registro histórico (Passos, 1966). Tinha o intuito de amparar os portugueses que se encontravam longe da terra natal, em caso de doença ou mesmo de insucesso no trabalho. Atualmente ainda conta com alguns sócios remidos e atende principalmente a pacientes particulares e conveniados, reservando pequena cota de leitos (5\%) ao Sistema Único de Saúde (SUS).

Os surtos de febre amarela ocorridos em Campinas entre $1889 \mathrm{e}$ 1897 acarretaram a redução da população, em virtude das escassas condições higiênico-sanitárias da cidade e das habitações (Ribeiro, 1993). Em 1874, o número de habitantes em Campinas (31.397 habitantes) era praticamente o mesmo da cidade de São Paulo (31.385 habitantes), e a epidemia deixou um número desconhecido de vítimas. Outra grande epidemia, a de gripe espanhola, em 1918, também abateu-se sobre a cidade, como em quase todo o país, conforme atestam vários estudos (Silva, 1996; Bertolli Filho, 2003; Bertucci-Martins, 2005).

Um ano após a abolição da escravatura e durante o período de intensa imigração de trabalhadores europeus, as condições de vida ainda eram muito precárias e não existia muito investimento público com higiene e saneamento básico (Santos Filho, Novaes, 1996). A descrição das condições dos imigrantes no final do século XIX 
refere opressões, males, condições nutricionais insuficientes, má remuneração e condições ruins de moradia, falta de assistência médica e escolas, condições estas muito semelhantes às enfrentadas durante séculos pelos escravos negros nas fazendas (Ribeiro, 1993).

Algumas instituições hospitalares reservaram um setor especial para receber excepcionalmente esses doentes estrangeiros, como o Circolo Italiani Uniti - atual Casa de Saúde de Campinas - e a Sociedade Portuguesa de Beneficência. O Diário de Campinas de 14 de março de 1889 destacava que a Beneficência abrira suas portas para pensionistas e indigentes portugueses vítimas da febre e para pacientes não portugueses. Esse procedimento também está documentado na publicação de Passos (1966).

Após as grandes epidemias, muitas instituições hospitalares se instalaram na cidade para suprir a demanda (Quadro 2). Em 1903 foi inaugurada a Maternidade de Campinas, nascida da necessidade de se ter um hospital municipal que atendesse "a mãe carente" (Revista..., 1983). Em 1910 cedeu-se um terreno de $2.688 \mathrm{~m}^{2}$, na avenida Andrade Neves, local onde hoje se localiza a Estação Rodoviária, para a instalação da Maternidade, que ali funcionou até 1965. Foi transferida posteriormente para a avenida Orozimbo Maia, e sua estrutura foi utilizada para a instalação provisória da Escola de Medicina da Unicamp. Atualmente o Hospital Maternidade de Campinas atende a pacientes particulares, conveniados e principalmente a pacientes do SUS.

O Hospital Álvaro Ribeiro foi fundado em 1933 pela Associação Protetora da Infância e inaugurado em 1936, por iniciativa do jornalista que deu nome à instituição. Prestava assistência às crianças pobres de Campinas. Na época a mortalidade infantil era muito elevada, em razão das condições habitacionais insalubres, da alimentação precária, do abuso do álcool e da falta de asseio, entre outros motivos referidos por uma comissão que avaliou suas causas (Ribeiro, 1993). Atualmente atende apenas a pacientes particulares e conveniados.

Aos 13 de agosto de 1933, a Associação Protetora da Infância fundou o Hospital, que só foi inaugurado em 17 de outubro de 1936. A Fundação da Álvaro Ribeiro começou com apenas um ambulatório e mais tarde já abriam suas portas as enfermarias com 53 leitos disponíveis. (Diário do Povo, Campinas, 13 out. 1963)

A partir da década de 1940, as instituições hospitalares passam a ser instaladas em Campinas por outras razões, como o desenvolvimento urbano, científico e tecnológico da cidade e da região. A fundação de hospitais foi intensa entre o final do século XIX e a década de 1940, bem como na década de 1970. 
Quadro 2 - Histórico dos hospitais da cidade de Campinas

\begin{tabular}{|ll|}
\hline Instituição & $\begin{array}{l}\text { Data de fundação } \\
\text { ou inauguração }\end{array}$ \\
\hline Santa Casa de Misericórdia de Campinas & 1876 \\
Hospital Beneficência Portuguesa & 20 jul. 1879 \\
Maternidade de Campinas & 12 out. 1903 \\
Hospital dos Socorros Mútuos & 1904 \\
Casa de Saúde de Campinas (Circolo Italiani Uniti) & 1918 \\
Hospital Irmãos Penteado & 1936 \\
Bierrenbach de Castro & 3 maio 1936 \\
Hospital Álvaro Ribeiro & 17 out. 1936 \\
Hospital Vera Cruz & 1943 \\
Clínica Dr. Celso Pierro & 1949 \\
Clínica Santo Antônio & 13 jun. 1961 \\
Clínica Lane & 20 jun. 1965 \\
Centro Médico de Campinas & 16 abr. 1973 \\
Clínica de repouso Qui-si-sana & 25 ago. 1973 \\
Hospital Boldrini & 25 jan. 1978 \\
Hospital das Clínicas & 15 fev. 1979 \\
Hospital Dr. Celso Pierro & 3 mar. 1979 \\
Sobrapar & 19 maio 1979 \\
Maternidade Albert Sabin & 1 abr. 1989 \\
\hline
\end{tabular}

\section{As transformações das dietas hospitalares}

Na análise de transformações históricas da alimentação hospitalar, focalizaram-se três processos: sua produção e distribuição, as dietas hospitalares e a relação com os pacientes.

Pelos procedimentos utilizados no planejamento e na produção da alimentação hospitalar, conclui-se que as dietas dos pacientes internados tinham as características de uma alimentação familiar e caseira. O serviço era prestado por religiosas e de caráter caritativo. O administrador entrevistado comentou a gestão dos serviços de internação, alimentação e rouparia pelas religiosas. $\mathrm{O}$ artigo "Assistência médica à criança pobre" (Diário do Povo, Campinas, 13 out. 1963) informava que as responsáveis pelos serviços de alimentação e limpeza do Hospital Álvaro Ribeiro eram religiosas de uma congregação contratada em 1957, para dirigir a cozinha e os serviços de limpeza: "Conta ainda o hospital com o abnegado trabalho das irmãs da Providência de Gap, que muito zelosamente, dirigem e orientam todos os trabalhos internos. Para os serviços gerais do ambulatório, limpeza, preparo de refeições, etc.".

O documento mais antigo encontrado foi o da Santa Casa de Campinas, datado de 1877, no qual se ressalta a preocupação com o asseio e a salubridade, esta proporcionada pela estrutura física 
do hospital, e com a higiene necessária para o controle de epidemias. Dietas gerais e específicas eram parte das medidas que visavam qualificar a instituição sob a gerência das freiras. $O$ rigor da dieta e alguns alimentos especiais eram atributos da qualidade do serviço hospitalar.

Ninguém há, que examinado o hospital não encontre nele resumidos as boas condições, salas espaçosas perfeitamente arejadas e iluminadas; boa disposição de leitos de modo a não permitir aglomeração de doentes; excelentes leitos perfeitamente guarnecidos de todos os seus utensílios indispensáveis; abundância de água que realiza o mais escrupuloso asseio. Bom sistema de latrinas que se não é o que há de mais perfeito é pelo menos o que se podia fazer de melhor, e que impede o acúmulo de materiais fecais no estabelecimento ou em sua proximidade; grandes banheiros que permitem os banhos gerais de asseio e os terapêuticos; excelente alimentação regulada por um quadro metódico de dietas tendo por base o que se faz em estabelecimentos idênticos e distribuída sob a inspeção da diretora da sala, em horas certas e determinadas, sendo ainda facultativo ao médico de acordo com as necessidades do doente, darlhes dietas específicas como leite, ovos, chocolate, bom vinho, etc., e por fim o serviço inteligente, dedicado, caritativo e desinteressado das Irmãs de S. José que colocam-se neste mester acima de tudo quanto delas se possa dizer. (Documento da Santa Casa de Campinas de 1877, acervo Irmandade de Misericórdia de Campinas (1971-1983), Arquivo Edgard Leuenroth; grifo nosso).

Referências a vinho, chocolate, leite, ovos e araruta, entre outros alimentos freqüentes na dieta hospitalar, são mencionadas por Nightingale em publicação de 1860 (Nightingale, 1989). Documentos acerca das dietas hospitalares prestam-se à observação das mudanças da nutrição como disciplina, do discurso e das representações sobre saúde e tratamento, que variam de acordo com o contexto sociocultural (Corbeau, 2005). Todavia tais mudanças apresentam nuanças, e ocorre também a permanência de certas práticas. O uso de gelatina na dieta hospitalar, por exemplo, era uma prática já criticada em 1860 (Nightingale, 1989).

Parte dos alimentos utilizados nos hospitais era produzida na própria instituição. Procedimento semelhante é relatado por Maes (1998), diretor honorário dos hospitais de Lyon, na França, que atesta a existência de hortas nos hospitais franceses na década de 1950, além de destacar que, na falta de alguns alimentos, recorriase aos fazendeiros vizinhos. O Relatório Anual de 1924 da Maternidade de Campinas registra a construção de um novo galinheiro no hospital, e no Relatório Anual de 1925 da mesma instituição há um informe sobre troca dos canos de um pomar, isto é, do sistema de irrigação das plantações. Conforme conta uma funcionária que foi copeira e cozinheira na Beneficência Portuguesa, também nessa 
instituição havia horta, pomar e galinheiro. Alguns funcionários dormiam no hospital para colher os alimentos pela manhã e preparar os animais criados no local para as refeições do dia. Outra entrevistada, que trabalhou em um hospital como copeira e depois tornou-se auxiliar de enfermagem, também relata: “Quando eu entrei aqui, trabalhava como copeira. Havia uma cozinheira que contava que, antigamente, ela chegava cedo e já tinha um pessoal depenando a galinha para fazer. Ela tinha muitas saudades, porque sempre contava para nós as mesmas histórias".

Na França, a monotonia alimentar e a alimentação insípida, com freqüência representadas pela presença constante da sopa, resultavam dos limites e da carência dos hospitais. Batatas em quantidade compradas na época da colheita, sem local adequado de armazenamento, germinavam precocemente e eram, então, aproveitadas na alimentação dos doentes (Maes, 1998). A variedade de alimentos nos cardápios era restrita e limitada porque dependia da produção da horta hospitalar. No contexto atual a monotonia dos cardápios parece persistir mais como um traço da cultura hospitalar do que propriamente pela escassez de itens alimentares (Garcia, 2006).

O valor da alimentação para a saúde e para a sua recuperação é reconhecido desde a Antiguidade, que tinha na dietética um dos ramos fundamentais da medicina, juntamente com a cirurgia e a farmacologia. A variedade, personalização, flexibilidade e moderação da alimentação, bem como a ingestão de alimentos cozidos e de fácil digestão eram preceitos de uma dieta saudável e também recomendados para o doente. Destacava-se a cocção como um processamento benéfico, que podia proporcionar propriedades terapêuticas ao alimento. O controle rigoroso da dieta pelo médico, caracterizado pelo comedimento na quantidade e por horários regulares da alimentação, visava restabelecer o doente e evitar a doença (Flandrin, Montanari, 1996). A alimentação hospitalar do século XIX, na França, constituída principalmente por carne, pão e queijo, era rigorosamente determinada por sexo, categoria de enfermidade e idade (Aron, 1973). O que se intitula atualmente gastronomia hospitalar pode expressar uma oposição aos limites e às restrições que tradicionalmente caracterizaram essa dieta.

No Arquivo Edgar Leuenroth da Unicamp encontra-se o Fundo Octavio Brandão - farmacêutico, poeta e anarquista nascido em 1896, em Alagoas, e falecido em 1980 no Rio de Janeiro. Em meio aos documentos manuscritos desse acervo há uma prescrição médica de dieta para "dispepsia de putrefação", da década de 1950, para um paciente com problema digestivo: 
Dieta Para Dispepsia de Putrefação

Nota: Não use alimentos riscados. As quantidades indicadas são referentes ao máximo permitido por dia. Não use alimento que não conste na relação abaixo.

Chá com sacarina, com açúcar (moderadamente).

Bolachas de água e sal, araruta ou maisena 40 a 50gr

Manteiga 40 a $50 \mathrm{gr}$

Queijo tipo coalho ou Minas 100gr

Arroz ou macarrão à vontade

Coalhada 250gr (retirar a gordura)

Bananas bem amassadas ou cozidas 1 a 2

Ovos 2 a 3 (quente)

Peixe (assado ou cozido) 1 vez por dia - em dias alternados, duas, três vezes por semana.

Cenoura e tomate $20 \mathrm{gr}$ cada

Outros alimentos permitidos: mamão, sapoti-lima, laranja doce. Faça este regime durante 20 dias.

Observação: procure fazer uma boa mastigação.

(Arquivo Edgard Leuenroth, HI/ DP.114)

Em 1847, uma descrição de alimentos diários no Hôtel Dieu, em Paris, designava, para cada pessoa, $373,7 \mathrm{~g}$ de pão, $272,8 \mathrm{~g}$ de carne, $13,4 \mathrm{~g}$ de peixe, $6,2 \mathrm{~g}$ de ave de criação, $2 / 3$ de um ovo, $175 \mathrm{cl}$ de leite, $190 \mathrm{~g}$ de legumes frescos, $55 \mathrm{~g}$ de batata, $9,4 \mathrm{~g}$ de queijo, $10 \mathrm{~g}$ de ameixas, $10 \mathrm{~g}$ de manteiga e $5 \mathrm{~g}$ de gordura (Aron, 1973). Tanto as descrições do repertório de alimentos quanto a precisão das quantidades assinalam o rigor no manejo das dietas hospitalares de então.

Na lista de alimentos usualmente utilizados para os pacientes, Nightingale (1989) já questionava, em 1860, a crença no valor nutritivo do caldo de carne e as vantagens da araruta como veículo para o vinho e como tônico de preparo rápido. Enaltecia os laticínios como os mais importantes alimentos para o doente, associados a farinhas como araruta, tapioca, sagu, trigo, aveia, cevada e outras. Criticava o uso exagerado da gelatina, de baixo valor nutricional, e do chá, entre outros alimentos, o que nos faz refletir sobre certos valores referentes à dieta hospitalar que se perpetuam. Muito do que foi mencionado por Nightingale se observa nas dietas hospitalares até a década de 1950, a exemplo da dieta para dispepsia e úlcera gástrica.

Na opinião do administrador hospitalar entrevistado, a alimentação, antes valorizada no tratamento hospitalar, cedeu lugar para a medicação:

Antigamente a nutrição era mais no alimento mesmo. Forneciase alimento, frutas recomendadas pelos médicos e produtos como carnes, cereais, verduras, legumes etc. ... Valorizava-se a alimentação para a recuperação, mas depois passou a depender muito mais da farmácia do que da alimentação natural ... A alimen- 
tação é apenas um dos itens ... Para os pacientes, é na área da farmácia mais do que alimentação. Na farmácia existe um capital razoável, porque é o principal produto para o paciente.

No início do século XX, os balanços anuais dos hospitais demonstram que os custos com o item alimentação eram mais elevados do que aqueles com medicamentos, conforme podemos ver, em valores da época, no Quadro 3.

Quadro 3 - Balanço da Maternidade de Campinas, 1925*

\begin{tabular}{|lc|}
\hline Item de dispêndio & Valor da despesa (em réis) \\
\hline Ordenado pessoal & $5: 826 \$ 400$ \\
Gratificação ao mesmo & $55 \$ 600$ \\
Alimentação & $2: 051 \$ 100$ \\
Despesas gerais & $3: 204 \$ 100$ \\
Drogas e medicamentos & $1: 185 \$ 600$ \\
\hline Total & $\mathbf{I 2 : 8 2 5} \$ \mathbf{8 0 0}$ \\
\hline
\end{tabular}

Fonte: Relatório da Maternidade de Campinas, 1925. (Centro de Ciências, Letras e Artes de Campinas/CCLAC).

*Parcialmente reproduzido.

De fato, o medicamento adquiriu papel central na medicina a partir da década de 1970, quando a farmacologia passou a dominar as estratégias terapêuticas (Dupuy, 1980), juntamente com intervenções mais complexas, que envolvem novas tecnologias. Tal mudança de foco refletiu na alimentação. Anteriormente, as dietas por sonda nasogástrica eram totalmente produzidas na cozinha hospitalar, utilizando-se alimentos in natura. Hoje, apesar de essas dietas ainda estarem presentes, sobretudo como indicação para uso domiciliar, observa-se nos hospitais a predominância de dietas produzidas pela indústria farmacêutica, compradas pelo serviço de nutrição ou pela farmácia hospitalar.

Uma das copeiras entrevistadas lembra como era o preparo das dietas por sonda: batiam o preparado, coavam e colocavam-no em garrafas de vidro, que eram então lacradas. Esse preparado baseava-se em ovos, farinha e outros alimentos.

A produção e a distribuição da alimentação hospitalar também sofreram mudanças quanto ao espaço físico e a instrumentos de trabalho. Os relatórios da Maternidade de Campinas informam sobre limpeza de paredes, pintura e reformas nos fogões a lenha da cozinha em 1924, 1926 e 1929, quando utilizavam um fogão provisório no rancho do hospital. O Relatório do Hospital da Beneficência Portuguesa de 1920 registra a reforma do prédio e a aquisição de "fogões novos, um a lenha e outro elétrico" (Passos, 1966, p.49).

A comparação da cozinha hospitalar com a cozinha de casa, em certo tom nostálgico, está presente no depoimento da copeira, ao focalizar instrumentos e ambiente de trabalho: 
Quando eu comecei no hospital... já se usava o fogão a gás, mas uma amiga que era cozinheira e que já faleceu ... contava para nós que gostava muito quando cozinhava no fogão a lenha porque era como na casa dela, e que depois que chegou o fogão a gás ela tinha mais dificuldade, e que a cozinha no inverno, com o fogão a gás, ficava sempre fria, gelada. Nisso ela tinha razão. Ela contava ainda que depois que acabavam o serviço, às vezes, ficavam por um tempo em volta do fogão, conversando.

Objeto de estudo de Certeau, Giard e Mayol (2000), o papel do fogão a lenha é analisado por sua utilidade na conservação dos alimentos, facilitada pela defumação, e no aproveitamento de alimentos excedentes, bem como na preparação de compotas de doces de frutas. O depoimento de uma das cozinheiras é exemplar, no que concerne a tais práticas de conservação dos alimentos e à comparação com os hábitos domésticos: "Aqui no hospital, eu não sei bem como fazia para conservar, mas acho que era como no sítio, na casa ... Em todo lugar a gente guardava os alimentos no sal ou na gordura. Era trabalhoso, mas não existia geladeira, e muito menos freezer."

A Maternidade de Campinas adquiriu seu primeiro refrigerador elétrico em 1933. Era uma "refrigeradeira General Eletric" [sic] conforme consta nos relatórios da Maternidade de Campinas -, fabricada nos Estados Unidos desde 1920 e, no Brasil, a partir da década de 1950. E uma das cozinheiras entrevistadas lembra que a preparação da comida no fogão elétrico era mais lenta, e que só em 1990 o hospital onde trabalhava adquiriu um fogão a vapor.

Certamente a renovação de equipamentos modifica tempo e espaço de preparo de alimentos, e reflete na produção e distribuição de refeições. Os quartos tinham uma mesa que era arrumada para as refeições, como lembra uma das entrevistadas, ex-copeira: "Os faxineiros, antes das refeições, arrumavam a mesinha com toalha, guardanapo, uma jarra de água e um copo para todos os pacientes. Arrumavam direitinho, bonitinho. A toalhinha branca, limpinha, tudo direitinho para cada paciente, aí a gente levava a comida."

Observam-se, nos depoimentos, afirmações de que no passado havia um lado 'mais humano' no serviço prestado pelo pessoal do setor de alimentação hospitalar. Quando necessário, a copeira que distribuía a refeição ajudava o paciente a se alimentar, apesar de ser esta uma função do enfermeiro, conforme referiu uma copeira. Hoje, a padronização de procedimentos e as competências dos profissionais são mais rígidas e impedem a flexibilização de responsabilidades.

Processos semelhantes aos domésticos caracterizavam a produção e distribuição dos alimentos nos hospitais. Os depoimentos acusam uma valorização daqueles procedimentos, tidos como naturais, com os quais se detinha o controle de boa parte da cadeia produtiva da alimentação. Tal valorização é mais próxima das representações 
sociais e simbólicas da própria sociedade brasileira, no período entre as últimas décadas do século XIX e meados do século XX, antes do projeto de industrialização do Estado nacional-desenvolvimentista.

É importante sublinhar que a revolução industrial do século XVIII já havia instituído a empresa industrial capitalista e seu símbolo, a fábrica, apartada da unidade produtiva familiar. Criou-se então uma certa racionalidade de organização e gestão que se estendeu a todas as sociedades industrializadas, atingindo as relações sociais. $\mathrm{O}$ trabalho passou a ocupar lugar central na vida dos indivíduos, sinônimo de cidadania e identidade, baseado em uma ética que não se reduz à necessidade e ao dever de trabalhar, mas que é moralmente válido para justificar toda a rede de relações que se estabelece no conjunto geral das instituições (Silva, 1995). Em descompasso com tais mudanças, observamos, nos documentos pesquisados e nas entrevistas realizadas, representações de valorização de conhecimentos práticos domésticos relativos à cozinha, assim como de ações relacionadas com a acolhida do visitante, com grande influência ainda da disciplina moral construída na fé, na vida religiosa, na assistência social aos pobres e enfermos.

Vimos que a dieta hospitalar era preparada artesanalmente na cozinha, com fogão a lenha ou a carvão. Quanto aos alimentos, grande parte deles era produzida no próprio espaço da instituição, em hortas, pomares e galinheiros, e complementada por compra de cereais e carnes. As despesas dos hospitais com alimentos naturais eram proporcionalmente maiores do que com medicamentos farmacêuticos. A responsabilidade pela receita da dieta era do médico, auxiliado por religiosas nas enfermarias, que podiam ser grandes e exigir grande número de copeiras para servir a alimentação e para a limpeza em geral do hospital.

Mesmo a distribuição da comida sendo diferenciada - até a porta em alas de pacientes de assistência pública, ou até o quarto em alas de pacientes particulares -, o envolvimento do pessoal encarregado da tarefa exigia um período maior de trabalho. A tarefa era feita por meio de carrinhos, que transportavam grandes panelas. Em certas instituições, porém, a cozinha do hospital funcionava como um refeitório, com grande movimentação, tanto das equipes de trabalho quanto de pacientes, podendo ainda atender às crianças do orfanato, à 'escola de moças' ou ao grupo do asilo, como acontecia na Santa Casa de Campinas. Em vários hospitais, a separação física da cozinha e do refeitório ocorreu apenas na década de 1970 (Nogueira, Lopes, 2003).

O ritual da alimentação hospitalar podia propiciar a instauração de relações afetivas com os pacientes, graças à associação atribuída culturalmente entre o ato de assistência social e o ato de comer. Criava-se, assim, um conjunto de sociabilidades ligadas ao momento da refeição, com expectativas de troca de intimidades, de 
familiaridades, especialmente em uma situação de fragilidade biológica e emocional por parte dos enfermos.

Atualmente, as copeiras mais novas não ajudam os pacientes a se alimentarem, conforme afirmou uma das copeiras entrevistadas. Segundo ela, a atividade de alimentação dos pacientes sempre coube aos enfermeiros, e hoje, com as funções mais bem definidas e hierarquizadas e com a busca por maior eficiência técnica e racionalidade, o convívio com os pacientes torna-se cada vez mais restrito e impessoal.

Na década de 1970, com a separação entre assistências social e hospitalar, as religiosas afastaram-se do setor de alimentação e voltaram-se para o trabalho nas capelas, ao mesmo tempo em que as nutricionistas começavam a ingressar nos hospitais de Campinas. Em alguns casos, criavam-se na mesma época os primeiros vínculos dessas instituições com as universidades, a exemplo da Santa Casa, que instalou o Hospital das Clínicas da Unicamp (Nogueira, Lopes, 2003).

As transformações do capitalismo industrial em meados do século XX até os processos de desenvolvimento pós-industrial, científico e tecnológico da sociedade contemporânea alteraram em grande medida a cultura institucional, situação em que se incluem os hospitais e o setor de alimentação. As sociedades pós-industriais, em que o Brasil se insere a partir da década de 1980, baseiam-se fundamentalmente na tecnologia, na informação e no conhecimento. A centralidade da organização social hoje em andamento apóia-se no conhecimento e altera a natureza do trabalho que antes, pouco qualificado, favorecia uma relação direta entre a natureza e a produção de mercadorias. Enfatiza-se crescentemente o trabalho que depende de relações entre técnicos, profissionais e especialistas, ou as tarefas técnicas em linhas de produção automatizada. O setor de serviços cresce em detrimento do setor produtivo industrial, especialmente os chamados serviços humanos em saúde, educação e serviços sociais, bem como os serviços profissionais e técnicos (Silva, 1996).

Esse contexto de profundas modificações afeta intensamente o mundo e a ética do trabalho. Sua fragmentação suscita o debate acadêmico sobre a centralidade da organização das sociedades contemporâneas (Antunes, 1999; Offe, 1989). A nova racionalidade de gestão empresarial estende-se a outras esferas da vida social. Tal racionalidade é baseada em estratégias de terceirização do trabalho, flexibilização e desqualificação de funções tradicionais, redução de custos e, ao mesmo tempo, crescentes meios tecnológicos de aumento da produtividade, de modo a enfrentar a concorrência e as rápidas flutuações de mercado (Vargas, 1996).

Com a padronização maior dos processos de trabalho, reduz-se a influência individual do funcionário. Quando uma das cozinheiras começou a trabalhar, "tinha uma liberdade maior, inclusi- 
ve no tempero", afirma ela. Da mesma forma, conforme os relatos colhidos sobre o ato de alimentar os pacientes, observava-se maior preocupação com o acolhimento do doente do que com os campos de competência profissional. Hoje a atividade do copeiro - distribuir a refeição - e a do enfermeiro - oferecer a alimentação para o paciente - estão mais demarcadas na prática hospitalar.

Os suplementos nutricionais, atualmente produzidos por grandes laboratórios, são adquiridos muitas vezes pela farmácia hospitalar. Sua requisição e distribuição são responsabilidade da nutricionista. Esse conjunto de mudanças, que espelha um processo de racionalização técnica, ocorre desde as décadas de 1960 e 1970 - conforme a documentação pesquisada e os depoimentos - e provavelmente não foi incorporado de uma só vez.

Ao final da década de 1970 uma outra racionalidade institucional foi construída e hoje vigora na produção e distribuição da alimentação hospitalar, conseqüência também das complexas transformações do sistema público e privado de saúde do país. Algumas de suas muitas expressões são a cobrança, por parte das instituições, pela redução do tempo dedicado ao ato de servir a comida aos pacientes, assim como do número de pessoas empregadas na produção da comida. Outro exemplo é a substituição do conceito de 'cozinha hospitalar' por 'serviço de nutrição e dietética', simbolizando um dos vários processos de tecnicização do trabalho por que passam as instituições de saúde. Aqueles que trabalham nas cozinhas e copas hospitalares necessitam ser tecnicamente preparados para enfrentar novas e múltiplas especialidades, e observa-se maior interdependência entre os diversos profissionais de saúde nos hospitais (Nogueira, Lopes, 2003).

Porém a tecnicização do processo de alimentação hospitalar tem sido lenta, pois o setor depende de sua valorização, por parte dos gestores, para ganhar prioridade de investimento em equipamentos, infra-estrutura e recursos humanos. Órgãos reguladores como a Vigilância Sanitária têm imposto mudanças de procedimentos visando a qualidade sanitária da alimentação, o que também tem gerado mudanças e novas necessidades para os serviços.

Na documentação pesquisada e nos relatos de trabalhadores dos serviços de alimentação dos hospitais, observou-se que o setor de produção de refeições era independente do atendimento médico, responsável pela prescrição das dietas especiais. Atualmente os serviços de nutrição atendem aos objetivos de produção de refeições e de atenção nutricional e são de responsabilidade do nutricionista, responsável técnico pelo serviço.

Os primeiros cursos de graduação em nutrição foram instituídos em 1939, em São Paulo, e em 1940, no Rio de Janeiro (Canesqui, Garcia, 2005). Em Campinas os nutricionistas começaram a ingressar nas instituições hospitalares tardiamente, por volta da década 
de 1970. A atenção nutricional, que inclui ações de dietoterapia, passou a fazer parte das competências do nutricionista, mas ainda não se consagrou, na prática hospitalar, como plena responsabilidade desse profissional. Bosi (1996) observou, entre nutricionistas da área hospitalar, uma disparidade entre as competências autoatribuídas e aquelas de fato exercidas, que em geral são menos qualificadas e aquém das atribuições regulamentadas pela lei. Além das deficiências de formação, argumentadas por Bosi (1996) para justificar tal situação, os aspectos organizacionais impõem limites, hierarquias e ritmos.

O papel do serviço de nutrição hospitalar consistiu, durante muito tempo, em produzir refeições sob a gerência de freiras, tarefa para a qual não se necessitava competência tecnocientífica, mas sim disponibilidade caritativa. Esse histórico pode nos ajudar a entender as atuais dificuldades de inserção da atenção nutricional no âmbito dos serviços de nutrição, bem como a cisão entre o serviço de produção de refeições e a dietoterapia, a qual, por sua vez, é hoje atribuição tanto do médico quanto do nutricionista. Tais cisões, aliadas à permanência de uma mentalidade que considera a alimentação hospitalar uma atividade de apoio ao doente, podem justificar o pouco reconhecimento de sua função terapêutica, assim como a visão ainda predominante do respectivo serviço apenas como produtor de refeições.

O estudo realizado permite também analisar as dificuldades de qualificação da dieta hospitalar. Observa-se o avanço em suporte nutricional e na produção de suplementos nutricionais pela indústria farmacêutica, sem que, todavia, se atente para a qualificação da alimentação hospitalar, entendida aqui por seus atributos sensoriais, nutricionais e simbólicos. Destaca-se, nesse aspecto, a valorização do aspecto nutricional e o desvio da qualidade sensorial para a área de gastronomia hospitalar.

Todos esses processos, apesar da influência dos impactos econômicos, científicos, tecnológicos e socioculturais mais gerais, poderão ser mais ou menos controlados, otimizados e humanizados por sujeitos sociais, na relação entre os serviços de nutrição e os pacientes, conforme o contexto das políticas e programas da área, a cultura institucional e a história de cada um dos hospitais, sejam eles públicos ou privados (Berger, Luckmann, 1987; Garcia, 1996).

\section{Considerações finais}

O estudo revelou, de diferentes perspectivas, a importância histórico-sociológica e a dimensão cultural de antigas práticas alimentares em instituições hospitalares de Campinas, como desdobramento de um projeto mais amplo sobre representações sociais de dietas hospitalares (Garcia, 2006). 
Em primeiro lugar, é preciso sublinhar a ausência, em alguns casos, ou a precária situação de preservação documental acerca da alimentação hospitalar no país, o que prejudica o conhecimento tanto dos seus procedimentos tecnocientíficos quanto de seus aspectos econômicos e socioculturais. No período anterior às décadas de 1960 e 1970, parece ser mais grave a ausência de memória documental sobre o tema.

Outro problema, complementar ao primeiro, é a escassez de estudos sobre dieta hospitalar no país, não apenas no âmbito das ciências sociais, mas também no de nutrição e saúde pública. É preciso investir em pesquisas que aprofundem a análise de elementos originários de uma cultura hospitalar que desvenda muito do modo de vida, do processo de trabalho, das representações de saúde e doença, da produção e da distribuição da alimentação nesse universo institucional.

Os grupos que trabalham há mais tempo no setor de alimentação hospitalar são, predominantemente, de origem pobre. Uma parcela deles compõe-se de migrantes do interior do país e possui uma moral de trabalho muito semelhante àquela dos empregos e atividades exercidas anteriormente, de natureza doméstica, ao passo que os grupos sociais mais jovens possuem um comportamento mais racional e técnico. O primeiro grupo se ressente de uma desqualificação no trabalho relacionada a seu saber empírico, e percebe a valorização e a exigência de preparo técnico dos grupos mais jovens. A tecnicização do trabalho combina com uma divisão mais profissional e minuciosa de funções, que depende de formação especializada de nível médio ou superior. O processo de alimentação tornou-se mais complexo e compreende uma moral de competência técnica especializada para o trabalho, própria do avanço das tecnologias na área da saúde.

É possível afirmar que, não obstante esse avanço científicotecnológico prolongar e salvar cada vez mais vidas humanas (Augusto, 1996), permanece insuficiente o conhecimento das dimensões históricas, sociais, culturais e mesmo psicológicas que influenciam e atuam nas relações entre profissionais, técnicos e pacientes, no cotidiano das instituições hospitalares. Como o enfoque predominante atua sobre o corpo biológico do paciente, e de forma cada vez mais técnica, o poder que se exerce é crescente e independe da vontade e decisão de quem o recebe.

Os pacientes, também no que diz respeito à alimentação, estão limitados em seu direito de se colocarem como sujeitos sociais, de expressarem as origens de sua cultura, memória e identidade (Mintz, 2001) e de opinarem sobre a forma como estão sendo alimentados, uma vez que o modelo das tecnologias de saúde representa-os como 'máquinas biológicas', passivas e submissas ao tratamento, e igno- 
ra as raízes simbólicas e culturais das expectativas da cura que pressupõem também o ato de se alimentar.

A valorização de intervenções e ações que contemplam mais tecnologia em detrimento daquelas identificadas como atividades de caráter doméstico (Adam, Herzlich, 1996), como é o caso da alimentação, estimula os procedimentos ligados a novas tecnologias e produtos de caráter mais medicamentoso do que alimentar. Essa visão pode ter contribuído para certa negligência dos hospitais com a alimentação, considerada uma área de pouca importância.

\section{FONTES E REFERÊNCIAS BIBLIOGRÁFICAS}

\section{Fontes primárias}

Diário do Povo. Campinas. (Biblioteca Municipal de Campinas, pasta Saúde).

Coleção Irmandade de Misericórdia de Campinas (1871-1983). (Arquivo Edgard Leuenroth / Centro de Pesquisa e Documentação Social da Universidade de Campinas).

Coleção História da Industrialização. (Arquivo Edgard Leuenroth / Centro de Pesquisa e Documentação Social da Universidade de Campinas).

Fundo Otávio Brandão. (Arquivo Edgard Leuenroth / Centro de Pesquisa e Documentação Social da Universidade de Campinas).

Fundo Coletivo Feminista de Campinas. (Arquivo Edgard Leuenroth / Centro de Pesquisa e Documentação Social da Universidade de Campinas).

Relatórios da Maternidade de Campinas, 1916-1936. (Centro de Cultura Letras e Artes de Campinas).

\section{Referências bibliográficas}

Adam, Philippe; Herzlich, Claudine 1996

Antunes, Ricardo 1999

Aron, Jean-Paul 1973

Augusto, Maria Helena O.

1996

Baeninger, Rosana 1996

Berger, Peter;

Luckmann, Thomas 1987

Bertolli Filho, Cláudio 2003
O hospital como organização e lugar de produção do trabalho médico. In: Adam, Philippe; Herzlich, Claudine. Sociologia da doença e da medicina. Bauru: Edusc, p.105-120.

Os sentidos do trabalho: ensaio sobre a afirmação e a negação do trabalho. São Paulo: Boitempo.

Le mangeur du XIX siècle. Paris: Médiations.

Indivíduo, vida contemporânea e tecnologia em saúde. Saúde, cultura e sociedade, São Paulo, Caderno 2, p.3-22.

Espaço e tempo em Campinas: migrantes e a expansão do pólo industrial paulista. Campinas: Centro de Memória da Unicamp.

A construção social da realidade.

7.ed. Petrópolis: Vozes.

A gripe espanhola em São Paulo, 1918: epidemia e sociedade. São Paulo: Paz e Terra. 
Bertucci-Martins, Liane Maria 2005

Blackburn, G.L. et al. 1977

Bollet, Alfred Jay; Owens, Sally 1973

Bosi, Maria Lúcia M. 1996

Bristian, B.R. et al. 1974

Canesqui, Ana Maria; Garcia, Rosa Wanda

Diez

Certeau, Michel de; Giard, Luce; Mayol, Pierre 2000

Chizzoti, Antônio 1988

Coe, Rodney M. 1973

Corbeau, Jean Pierre 2005

Dupuy, Jean-Pierre 1980

Feliciello, Domenico 2002

Flandrin, Jean-Louis;

Montanari, Massimo 1996

Foucault, Michel 1996

Garcia, Rosa Wanda

Diez 2006

Garcia, Sylvia Gemignani 1996

Kandela, Peter 1999

Lang, Alice Beatriz da S.G.

1992
Aprendendo com o passado: Campinas e a gripe de 1918.

In: Simpósio Nacional de História, 22., 2005, Londrina. Anais suplementares. Londrina: Anpuh, v.1. p.1-8.

Nutritional and metabolic assessment of the hospitalized patient. Journal of Parenteral and Enteral Nutrition, Silver Spring, v.1, n.1, p.11-22.

Evaluation of nutritional status of selected hospitalized patients. American Journal of Clinical Nutrition, v.26, n.9, p.931-938.

Profissionalização e conhecimento: a nutrição em questão. São Paulo: Hucitec. 203p.

Protein status of general surgical patients.

The Journal of the American Medical Association, Chicago, v.230, n.6, p.858-60.

Ciências sociais e humanas nos cursos de nutrição. In: Canesqui, Ana Maria; Garcia, Rosa Wanda Diez. Antropologia e nutrição: um diálogo possível. Rio de Janeiro: Fiocruz. p.255-75.

A invenção do cotidiano: morar, cozinhar.

3.ed. Petrópolis: Vozes.

Pesquisas em ciências humanas e sociais.

São Paulo: Cortez.

El sentido de la hospitalizacion.

In: Coe, Rodney M. Sociologia de la medicina. Madrid: Alianza. p.331-363

Alimentar-se no hospital: as dimensões ocultas da comensalidade. In: Canesqui, Ana Maria; Garcia, Rosa Wanda Diez.

Antropologia e nutrição: um diálogo possível. Rio de Janeiro: Fiocruz. p.227-238

A invasão médica. In: Dupuy, Jean-Pierre.

Introdução à crítica da ecologia política. Rio de Janeiro: Civilização Brasileira. p.41-59.

Os projetos pedagógicos das escolas médicas no Brasil Império: uma contribuição para a avaliação do ensino superior no Brasil. Tese (Doutorado) - Faculdade de Ciências Médicas, Unicamp, Campinas.

História da alimentação.

São Paulo: Estação Liberdade.

Microfísica do poder.

12.ed. Rio de Janeiro: Graal.

A dieta hospitalar na perspectiva dos sujeitos envolvidos na sua produção e planejamento. Revista de Nutrição, Campinas, v.19, n.2, p.129-144.

Cultura, dominação e sujeitos sociais.

Tempo Social, São Paulo, v.8, p.159-177.

Sketches from The Lancet.

Hospital food. Lancet, London, v.353, n.9154, p.763.

Documentos e depoimentos na pesquisa histórico-sociológica.

In: Lang, Alice Beatriz da S.G. (Org.). Reflexões sobre a pesquisa sociológica. São Paulo: Ceru. p. 78-96. (Textos Ceru, série 2, n.3). 
Maes, Gérard

1998

McKee, Martin;

Healy, Judith 2002

Mintz, Sidney W. 2001

Neves, Lucília de Almeida

2000

Nightingale, Florence 1989

Nogueira, Lucas

Vinícius S.; Lopes, 2003

Offe, Claus 1989

Passos, Benedito da Cruz

Revista... 1966 1985

Revista... 1983

Ribeiro, Maria Alice

Rosa

1993

Santos Filho, Lycurgo de Castro; Novaes, José

Nogueira

1996

Silva, Josué Pereira da 1995

Silva, Kleber Pinto 1996

Vargas, Francisco Eduardo B.
La soupe à l'hôpital: témoignage. In: Assistance Publique - Hôpitaux Paris. L'appétit vient en mangeant! Histoire de l'alimentation à l'hôpital. XV-XX siècle. Paris: Edoin; Musée de l'Assistance Publique - Hôpitaux Paris. p.83-100.

The significance of hospital: an introduction. In: McKee, Martin; Healy, Judith (Ed.). Hospitals in a changing Europe. Buckingham: Open University Press. p.3-13.

Comida e antropologia: uma breve revisão.

Revista Brasileira de Ciências Sociais, Bauru, v.16, n.47, p.31-41.

Memória, história e sujeito: substratos da identidade.

História oral, São Paulo, n.3, p.109-116.

Notas sobre enfermagem: o que é e o que não é.

Trad.: Amália Correa de Carvalho. São Paulo: Cortez.

Perspectiva histórico-sociológica do serviço de nutrição dos hospitais: Santa Casa de Campinas, Casa de Saúde e Vera Cruz. Relatório de iniciação científica, Faculdade de Ciências Sociais, Pontifícia Universidade Católica de Campinas, Campinas.

Trabalho e sociedade: problemas estruturais e perspectivas para o futuro da sociedade do trabalho. Rio de Janeiro: Tempo Brasileiro.

Registro histórico da Real Sociedade Portuguesa de Beneficência, 1873-1960. Campinas: Saraiva.

Revista Comemorativa - 72 anos, Maternidade de Campinas. Campinas: Maternidade de Campinas.

Revista Comemorativa - 70 anos, Maternidade de Campinas. Campinas: Maternidade de Campinas.

História sem fim...: inventário da saúde pública. São Paulo, 1880-1930. São Paulo: Ed. Unesp.

A febre amarela em Campinas (1889-1900).

Campinas: Centro de Memória da Unicamp.

A crise da sociedade de trabalho em debate. Lua Nova, São Paulo, n.35, p.167-181.

A cidade, uma região, o sistema de saúde: para uma história da saúde e da urbanização de Campinas-SP. Campinas: Centro de Memória da Unicamp.

Trabalho e desigualdades nas sociedades contemporâneas: um esboço para a reflexão. Cadernos do ISP, Pelotas, v.8, p.47-58.

Recebido para publicação em janeiro de 2006. Aprovado para publicação em setembro de 2006. 